\title{
Functional Trait Responses to Strip Clearcutting in a Moso Bamboo Forest
}

\author{
Yaxiong Zheng ${ }^{1,2}$, Fengying Guan ${ }^{1,2, *}$, Shaohui Fan ${ }^{1, *}$, Yang Zhou ${ }^{1}$ and Xiong Jing ${ }^{1}$ \\ 1 International Center for Bamboo and Rattan, Key Laboratory of National Forestry and Grassland \\ Administration, Beijing 100102, China; zhengyaxiong502@163.com (Y.Z.); zhyx@icbr.ac.cn (Y.Z.); \\ jingx@icbr.ac.cn (X.J.) \\ 2 National Location Observation and Research Station of the Bamboo Forest Ecosystem in Yixing, \\ National Forestry and Grassland Administration, Yixing 214200, China \\ * Correspondence: guanfy@icbr.ac.cn (F.G.); fansh@icbr.ac.cn (S.F.)
}

Citation: Zheng, Y.; Guan, F.; Fan, S.; Zhou, Y.; Jing, X. Functional Trait Responses to Strip Clearcutting in a Moso Bamboo Forest. Forests 2021, 12, 793. https://doi.org/10.3390/ f12060793

Academic Editor: Giorgio Alberti

Received: 6 May 2021

Accepted: 10 June 2021

Published: 16 June 2021

Publisher's Note: MDPI stays neutral with regard to jurisdictional claims in published maps and institutional affiliations.

Copyright: (c) 2021 by the authors. Licensee MDPI, Basel, Switzerland. This article is an open access article distributed under the terms and conditions of the Creative Commons Attribution (CC BY) license (https:// creativecommons.org/licenses/by/ $4.0 /)$.
Abstract: Functional characteristics reflect plant strategies and adaptability to the changing environment. Determining the dynamics of these characteristics after harvesting would improve the understanding of forest response strategies. Strip clearcutting (SC) of moso bamboo forests, which significantly reduces the cutting cost, has been proposed to replace manual selective harvesting. A comparison of restoration features shows that $8 \mathrm{~m}$ is the optimal cutting width. However, the precise response of functional features to the resulting harvest-created gap remains unclear. In this study, three SC plots were selected which was performed in February 2019, with three unharvested plots as a control (C). The study focused on 10 functional traits, including leaf area (LA), specific leaf area (SLA), leaf dry matter content (LDMC), leaf nitrogen content (LNC), leaf phosphorus content (LPC), nitrogen/phosphorus ratio (N:P), wood density (WD), fine root biomass (FRB), specific fine root length (SRL), and root length density (RLD). A one-way ANOVA was used to compare differences in functional traits and soil nutrients between treatments. Strip clearcutting significantly reduced the soil organic carbon (SOC) and total nitrogen (TN) contents $(p<0.05)$. In terms of functional characteristics, SC significantly decreased LA and increased LNC, LPC, and N:P $(p<0.05)$. However, $\mathrm{SC}$ had no significant effect on fine root traits $(p>0.05)$. This study highlighted that root trait, soil content of total phosphorus (TP) and total potassium (TK) returned to the level of uncut plots after a year's recovery. The LPC, LNC, and N:P were negatively correlated with LA, and LDMC and WD were negatively correlated with SLA, while the effect of SC on fine root traits was limited $(p>0.05)$. Fine root traits (FRB, RLD, and SRL) were positively associated with SOC, TN, and TP, but negatively correlated with TK. The changes in soil nutrient content caused by the removal of biomass were normal. Increased light and the rapid growth of new trees will increase nutrient regressions; therefore, these results further confirm the feasibility of SC.

Keywords: moso bamboo forest; strip clearcutting; functional traits; soil nutrients

\section{Introduction}

China has an extensive range of bamboo species, which are widely distributed in the country. Moreover, China was the first country to utilize bamboo in construction materials, food, furniture, biomass energy, and other fields [1]. More than 500 species of bamboo, from 39 genera, are found in 13 provinces in China [2]. Moso bamboo (Phyllostachys edulis (Carrière) J. Houz.) covers 4.67 million ha, accounting for $72.96 \%$ of the total bamboo forest area [2]. However, the high cost of harvest, caused by a shortage of labor, has become a practical problem in its production. This expense has also reduced the interest in artificial management, and many bamboo plantations are now neglected. High densities of moso bamboo adversely affect understory vegetation and nutrient cycling [3]. These problems have reduced productivity and bamboo production, and ultimately have serious effects on 
the sustainable management of plantations. There is, therefore, increasing demand for cost reductions in the management of moso bamboo forest.

Strip clearcutting (SC) has been proposed as a solution to the aforementioned problems in moso bamboo forests. Wang et al. [4] proposed the model of strip cutting to reduce the labor shortage for Phyllostachys glauca forest management, based on cloning integration characteristics. Mother bamboo trees provide nutrients to shoots and new trees in the cutting area through clonal integration within a certain distance, and this distance of nutrient transport has no effect on the development of mother bamboo, which is defined as the effective distance. Moreover, the improved quality of new trees validated the effective distance of nutrient transport [4]. Clonal integration has little negative influence on the growth of new bamboo in the reserved belt, suggesting that the SC model is feasible [4]. A field experiment on moso bamboo set different cutting widths, and examined several indexes (including the number of shoots and new trees, diameter at breast height (DBH), biomass, chlorophyll, reducing sugar, and soluble protein) in postharvest plots, and recommended an $8 \mathrm{~m}$ width as the optimal size [5,6]. However, studies have shown that harvesting alters the understory species, soil conditions, and microbial activity [7].

Functional traits reflecting plant strategies and adaptability to the environment [8] can be used to evaluate the resilience of a community to disturbance. Functional traits have increasingly been used to establish a model to predict the response mechanism of ecological communities to abiotic disturbance [9]. Changes in the availability of any resource trigger alterations in functional traits determining the ability of plants to access that resource [10]. One hypothesis is that resource stress that breaks through the tolerance of plants leads to higher growth potential, reflecting the tradeoff between rapid resource acquisition and conservation [11]. Forest succession after natural disturbance reveals general changes in functional traits [12]. Five years after thinning took place, the community weighted mean value of seedling specific leaf area (SLA) decreased significantly, while wood density and mean maximum height increased [13]. High SLA means less dry matter investment, higher growth rate, and shorter life span, indicating a resource scarcity in the development of plants [14]. Moso bamboo has higher phenotypic plasticity to heterogeneous habitats due to its clonal growth [15]. Cloning integration reflects the fact the stem growth is supported by carbohydrates from the mother plant, rather than its own photosynthesis $[16,17]$. When moso bamboo expands into broad-leaved forest, it adopts certain measures to adapt to a different habitat $[18,19]$. In this framework, trait variation is considered to be related to changes in environmental factors.

Previous research on moso bamboo forests has mainly focused on how cutting affects aboveground growth and soil nutrients; however, the effect of cutting at the effective distance on a functional trait is still unclear $[5,6,20,21]$. Improving understanding of how functional traits respond to $\mathrm{SC}$ is crucial for the sustainable management of bamboo forest ecosystems, from the perspective of nutrient capture ability. In this study, SC was conducted on plots with a width of $8 \mathrm{~m}$, with the unharvested plot as the control (C). The hypothesis is that plant tolerance will not be affected by SC at the optimal width. Therefore, there will be no significant differences in functional traits between the two treatment sites. There will be a correlation between soil nutrient factors and functional traits. The following questions were investigated: (1) do differences in functional traits occur between new trees in the harvested (SC) and unharvested plots? To compare changes in growth strategies, data were collected from a wide range of traits, including leaf traits, wood traits, fine root traits, and nutrient elements; (2) what effect do soil factors have on functional traits after harvesting? A correlation analysis was used to determine this.

\section{Material and Methods}

\subsection{Site Description}

This study was conducted in the Yixing Forest Farm $\left(25^{\circ} 50^{\prime} 36^{\prime \prime}-2^{\circ} 26^{\prime} 30^{\prime \prime} \mathrm{N}, 117^{\circ} 48^{\prime} 30^{\prime \prime}-\right.$ $118^{\circ} 40^{\prime} \mathrm{E}$ ), in southern Jiangsu Province, China. This region is dominated by low mountain and hilly terrain, and the soil type is yellow clay, according to the classification and codes 
for Chinese soil (GB/T 17296-2009). The area is characterized by a maritime monsoon climate, with an annual average temperature of $15.7^{\circ} \mathrm{C}$ and precipitation of $1167 \mathrm{~mm}$. The weather is characterized by four distinct seasons, plenty of sunshine, and high humidity. The growing period can continue for approximately 250 days. The farm was established in March 1950 and had 120 ha of monodominant moso bamboo forest. There were no pests and diseases, and no fertilization treatments in the region. The average $\mathrm{DBH}$ and bamboo heights are $8.13 \mathrm{~cm}$ and $13.37 \mathrm{~m}$, respectively, and the average tree density is 3375 stems ha ${ }^{-1}$. Moso bamboo has a particular characteristic; it has a two-year vegetative cycle called 'du', which includes both an 'on-year' and 'off-year'. On the farm, it is obvious when moso bamboo is in an on-year and when it is in an off-year [22]. The prominent understory species include Hedyotis chrysotricha, Carex breviculmis, Paederia cruddasiana, Oxalis corniculata, and Salvia prionitis.

Strip clearcutting means cutting down all the trees in the plot and taking the whole plant out of the experiment site. A complete rotation system reserved two belts between each cut belt, cutting one reserved belt after the cutting belt restoration, and then cutting another reserved belt after the reserve-belt cut restoration. The function of the reserved plots was to provide nutrients to the strip-cut belts through physiological integration. In other words, each cut plot had two retention plots to provide nutrients for the recovery period. No management practice was conducted in the harvest plots and reserve plots during the restoration period. The test was performed in an area with uniform environmental and topographical quality. This study design had two different types of treatment: plots that underwent SC in February 2019, and unharvested plots (C). Cutting plots were $24 \mathrm{~m} \times 20 \mathrm{~m}$, including an SC belt $(8 \mathrm{~m} \times 20 \mathrm{~m})$, and two reserved plots of the same size. Meanwhile, four trenches $(50 \mathrm{~cm}$ width $\times 50 \mathrm{~cm}$ depth) were excavated around the plot to cut off rhizomes to stop the influence of long-distance nutrient transport. The $\mathrm{C}$ treatment with $(8 \mathrm{~m} \times 20 \mathrm{~m})$ uncut plots was also included. Each treatment was replicated three times; a total of six plots was established, and the distance between each treatment plot was less than $50 \mathrm{~m}$. The study area slope was approximately $6^{\circ}$. New shoots began to emerge in April 2019 and turned into trees in July 2019.

\subsection{Leaves and Branch Sampling and Analysis}

Fresh leaves were collected in October 2020. In the postharvest plot, 30 leaves were taken at different heights from each new tree, and a total of 2280 leaves were collected. The investigation of leaves was based on trees of the same age, as no shoots grew within a year of recovery. Therefore, 12 trees that matured in 2019 were randomly selected from each unharvested plot, and a total of 1080 leaves were collected. The petiole was removed and the leaf was soaked in water and kept in darkness for $12 \mathrm{~h} \mathrm{[18].} \mathrm{The} \mathrm{surface} \mathrm{water}$ was wiped with absorbent paper and weighed (fresh weight) using an electronic balance $(0.0001 \mathrm{~g})$. Leaf characteristics were scanned using a ScanMaker i800 scanner and stored as JPEG files (300 dpi). The leaf area (LA) analysis software (WSeen's Leaf Area Analysis System, model_LA-S, China) was used to analyze the leaf size. After analysis, leaves were oven-dried at $65{ }^{\circ} \mathrm{C}$ for $48 \mathrm{~h}$ to a constant weight, and then weighed. Specific leaf area (SLA) is an important index that reflects plant adaptability to light, nutrient, and community environments [11]. The leaf dry matter content (LDMC) can reflect the leaf carbon economy [11] and shows more variation than SLA [18]. The leaf nitrogen content (LNC) and leaf phosphorus content (LPC) reflect the capacity to photosynthesize and use mineral elements [11], and the nitrogen-phosphorus ratio (N:P) is commonly used to assess nutrient elements that limit community productivity [23]. Wood density (WD) reflects the variation in water acquisition strategies [12]. In this study, SLA was expressed as the ratio of fresh leaf area to dry mass [18]. The leaf dry matter content was expressed as the ratio of dry mass to fresh mass [18]. Leaf nitrogen content was determined using an elemental analyzer (Costech ECS 4024 CHNSO, Picarro, Italy). Leaf phosphorus content was determined following the molybdenum-antimony resistance colorimetric method (concentrated H2SO4-HCLO4) using an automatic chemical analyzer (Smartchem 300, 
AMS, Italy). To avoid any negative effects of wood density survey sampling on new tree growth, 1-2 cm long branches were used instead of the trunk core. The calculated WD refers to the Chinese testing methods for physical and mechanical properties of bamboo (GB/T 15780-1995) [24].

\subsection{Fine Root Sampling and Analysis}

The fine root sampling was conducted in October 2020, when growth was slow [25]. Ten cores (70 mm diameter, $10 \mathrm{~cm}$ height) were sampled along the median line of each plot. Sampling was divided into 0-10, 10-20, and 20-40 cm, and these layers contained almost all of the fine roots [26]. The roots and soil were separated by a $2.0 \mathrm{~mm}$ sieve, then washed with running water on a $0.49 \mathrm{~mm}$ sieve. The roots were put into an evaporating dish and classified using a vernier caliper, tweezers, and a magnifying glass. The live and dead roots were identified according to configuration, color, and elasticity [26]. In this study, a diameter $<2 \mathrm{~mm}$ was defined as the fine root [26]. The fresh fine roots were weighed by an electronic balance $(0.0001 \mathrm{~g})$ and scanned by a ScanMaker i800 scanner, and images were stored as JPEG files (300 dpi). The root analysis system (WSeen's Root Analysis System, model_LA-S, China) was used to analyze the fine root length (RL, cm). The roots were oven-dried at $65{ }^{\circ} \mathrm{C}$ to a constant weight to obtain the root dry mass (RDM, g). Specific root length (SRL, $\mathrm{cm} \mathrm{g}^{-1}$ ) indicates morphological and physiological functions [26]. The root length density ( $R L D, \mathrm{~m} \mathrm{~m}^{3}$ ) is an important index of nutrient absorption and water absorption capacity of fine roots; the higher RL density, the greater surface area of absorption [26]. The fine root biomass (FRB, $\mathrm{g} \mathrm{m}^{3}$ ), SRL, and RLD were calculated with the following equations [26]:

$$
\begin{gathered}
\mathrm{FRB}=\mathrm{RDM} /\left[\pi(d / 2)^{2} \times h \times 10^{-6}\right] \\
\mathrm{SRL}=\mathrm{RL} / \mathrm{RDM} \\
\mathrm{RLD}=\mathrm{RL} /\left[\pi(d / 2)^{2} \times h \times 10^{-6}\right]
\end{gathered}
$$

where $d$ is the diameter of the core $(\mathrm{cm})$, and $h$ is the height of the core $(\mathrm{cm})$.

\subsection{Soil Sampling and Chemical Analysis}

In each plot, sequential soil coring was used to extract 10 soil cores in October 2020. Sampling was conducted at $0-10 \mathrm{~cm}, 10-20 \mathrm{~cm}$, and $20-40 \mathrm{~cm}$. Cores from the same layer were mixed as one composite sample. Coarse roots were removed from the mixed samples using a $2 \mathrm{~cm}$ sieve, and then soil chemical properties were determined after air-drying. The contents of soil organic carbon (SOC) and total nitrogen (TN) were determined using an elemental analyzer (Costech ECS 4024 CHNSO, Picarro, Italy). Soil total phosphorus (TP) content was determined following the molybdenum-antimony resistance colorimetric method (concentrated $\mathrm{H}_{2} \mathrm{SO}_{4}-\mathrm{HCLO}_{4}$ ) using an automatic chemical analyzer (Smartchem 300, AMS, Italy). Soil total potassium (TK) content was determined by a flame photometer (M410, Sherwood, UK). Soil alkali-hydrolyzable nitrogen content (AN) was determined following the alkali-hydrolyzable diffusion method. A continuous flow analyzer (AA3, Seal, Germany) was used to determine the available soil phosphorus (AP) content. The content of available potassium (AK) was determined by flame atomic absorption spectrometry.

\subsection{Data Analysis}

A one-way analysis of variance (ANOVA) was used to test whether soil nutrient content and functional traits differed in the two treatment plots (SC vs. C). Assumptions of normality and homogeneous variance were examined by a Shapiro-Wilk test and a Leven test, respectively. Means were separated by the least significant difference test, and statistical significance was evaluated at $p<0.05$. A principal component analysis (PCA) was used to examine the associations between functional traits and stand and soil 
characteristics. All statistical analyses were performed in R (version 3.6.2), and data were collated using Excel 2016. The PCA was calculated with the 'FactoMineR' paCage. Graphs were drawn with the 'ggplot2' paCage.

\section{Results}

\subsection{Soil Characteristics}

The SOC and soil TN content decreased with depth in both treatment plots $(p<0.05)$. Moreover, cutting significantly reduced the SOC and TN in each soil layer, increased the content of AP in the 0-10 cm soil layer, reduced the content of TP in the 10-20 cm soil layer, and reduced the content of AN in the $20-40 \mathrm{~cm}$ soil layer $(p<0.05$, Table 1$)$.

Table 1. Soil characteristics for moso bamboo in strip clearcutting (SC) or unharvested (C) plots.

\begin{tabular}{|c|c|c|c|c|c|c|c|c|}
\hline Site & $\begin{array}{l}\text { Soil Layers } \\
\text { (cm) }\end{array}$ & $\begin{array}{l}\text { SOC } \\
(\mathrm{g} / \mathrm{kg})\end{array}$ & $\begin{array}{c}\mathrm{TN} \\
(\mathrm{g} / \mathrm{kg})\end{array}$ & $\underset{(\mathrm{g} / \mathrm{kg})}{\mathrm{TP}}$ & $\begin{array}{c}\text { TK } \\
(\mathrm{g} / \mathrm{kg})\end{array}$ & $\underset{(\mathrm{mg} / \mathrm{kg})}{\mathrm{AN}}$ & $\underset{(\mathrm{mg} / \mathrm{kg})}{\mathrm{AP}}$ & $\underset{(\mathrm{mg} / \mathrm{kg})}{\mathrm{AK}}$ \\
\hline \multirow{3}{*}{ SC } & $0-10$ & $27.20 \pm 0.54 \mathrm{Aa}$ & $2.15 \pm 0.07 \mathrm{Aa}$ & $0.28 \pm 0.02 \mathrm{Aa}$ & $9.17 \pm 0.57 \mathrm{Aa}$ & $167.95 \pm 15.06 \mathrm{Aa}$ & $5.66 \pm 0.85 \mathrm{Aa}$ & $50.61 \pm 6.02 \mathrm{Aa}$ \\
\hline & $10-20$ & $17.00 \pm 1.02 \mathrm{Ba}$ & $1.21 \pm 0.09 \mathrm{Ba}$ & $0.23 \pm 0.01 \mathrm{Ba}$ & $9.26 \pm 0.49 \mathrm{Aa}$ & $99.83 \pm 6.68 \mathrm{Ba}$ & $3.40 \pm 1.20 \mathrm{Ba}$ & $28.73 \pm 3.89 \mathrm{Ba}$ \\
\hline & $20-40$ & $9.74 \pm 0.67 \mathrm{Ca}$ & $0.87 \pm 0.03 \mathrm{Ca}$ & $0.24 \pm 0.02 \mathrm{Ba}$ & $9.37 \pm 0.45 \mathrm{Ba}$ & $60.52 \pm 9.94 \mathrm{Ca}$ & $1.42 \pm 1.00 \mathrm{Ba}$ & $23.13 \pm 4.32 \mathrm{Ba}$ \\
\hline \multirow{3}{*}{$\mathrm{C}$} & $0-10$ & $30.50 \pm 1.09 \mathrm{Ab}$ & $2.30 \pm 0.03 \mathrm{Ab}$ & $0.29 \pm 0.01 \mathrm{Aa}$ & $8.92 \pm 0.14 \mathrm{Aa}$ & $128.87 \pm 52.35 \mathrm{Aa}$ & $2.38 \pm 1.77 \mathrm{Ab}$ & $40.78 \pm 10.27 \mathrm{Aa}$ \\
\hline & $10-20$ & $21.93 \pm 1.17 \mathrm{Bb}$ & $1.72 \pm 0.03 \mathrm{Bb}$ & $0.26 \pm 0.01 \mathrm{Bb}$ & $9.05 \pm 0.07 \mathrm{Aa}$ & $130.81 \pm 43.23 \mathrm{Aa}$ & $2.61 \pm 1.72 \mathrm{Aa}$ & $40.82 \pm 10.29 \mathrm{Aa}$ \\
\hline & $20-40$ & $15.88 \pm 1.42 \mathrm{Cb}$ & $1.22 \pm 0.04 \mathrm{Cb}$ & $0.27 \pm 0.02 \mathrm{ABa}$ & $9.51 \pm 0.25 \mathrm{Ba}$ & $130.37 \pm 41.30 \mathrm{Ab}$ & $2.17 \pm 1.84 \mathrm{Aa}$ & $40.66 \pm 10.12 \mathrm{Aa}$ \\
\hline
\end{tabular}

Values are the mean \pm standard deviation $(n=3)$. Different lower-case letters indicate significant differences between SC and C in the same soil layer; different capital letters indicate significant differences between different soil layers at the same treatment (ANOVA and LSD test, $p<0.05)$. SOC: soil organic carbon; TN: total nitrogen; TP: total phosphorous; TK: total potassium; AN: alkali-hydrolyzable nitrogen; AP: available phosphorous; and AK: available potassium.

\subsection{Leaf Trait and Wood Density}

The LA of SC plots decreased significantly, compared to C plots, while the LNC, LPC, and N:P increased significantly (Figure $1, p<0.05$ ). There were no significant differences between SLA, LDMC, and WD in the two treatment plots $(p>0.05)$.
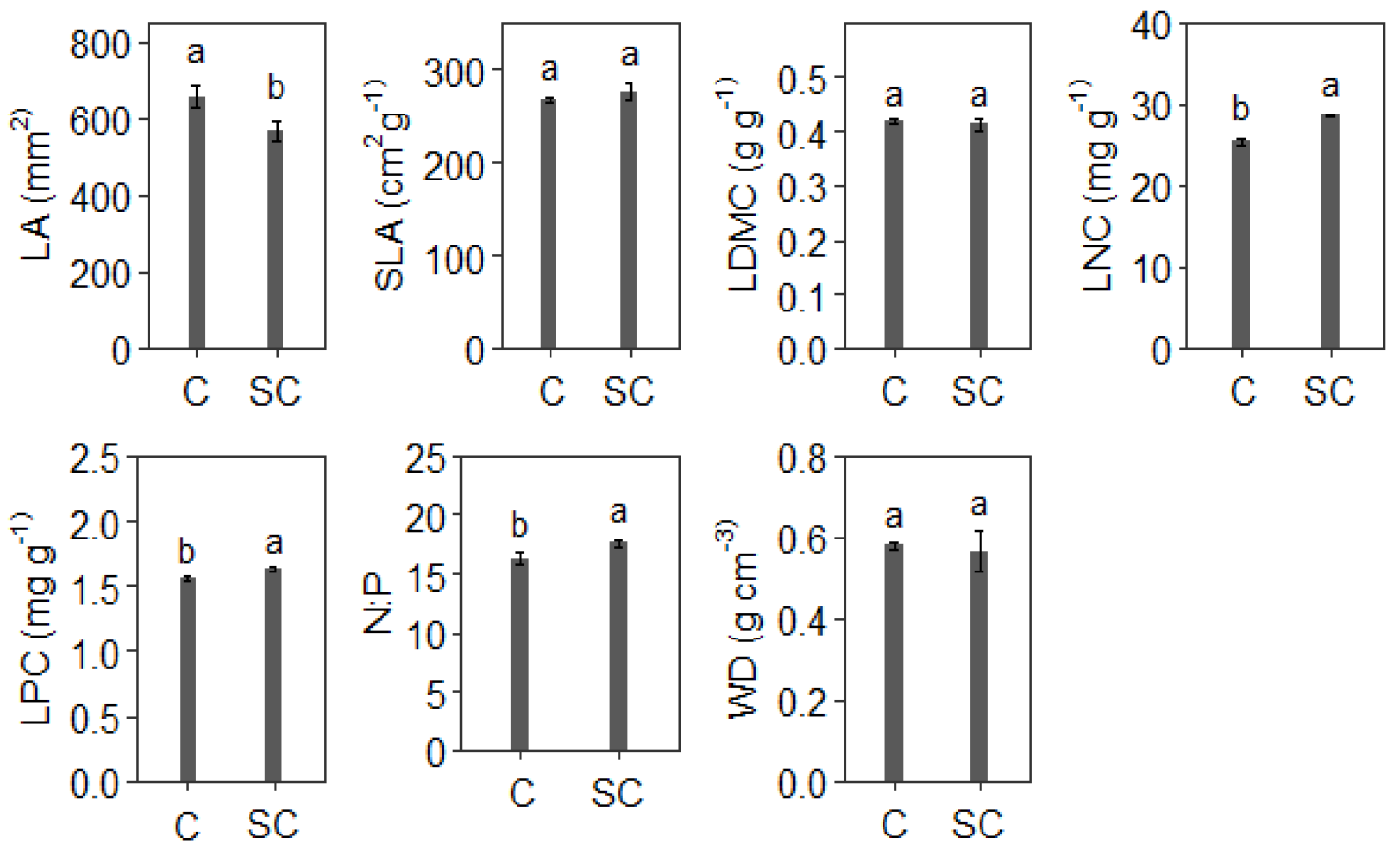

Figure 1. Leaf area (LA), specific leaf area (SLA), leaf dry matter content (LDMC), leaf nitrogen content (LNC), leaf phosphorus content (LPC), the nitrogen-phosphorus ratio (N:P), and wood density (WD) of moso bamboo in strip clearcutting (SC) and unharvested (C) plots. Error bars indicate the standard deviation $(n=3)$. Different letters indicate significant differences between the two treatment sites $(p<0.05)$. 


\subsection{Relationships between Leaf Traits, Wood Density, and Soil Nutrients}

As shown in Table 2, LA was significantly positively correlated with TN in the $0-10 \mathrm{~cm}$ soil layer, with SOC, TN, TP, and AK in the 10-20 cm soil layer, and with SOC, TN, AN, and AK in the $20-40 \mathrm{~cm}$ soil layer. The SLA was negatively correlated with TK content in the 20-40 cm soil layer, and the LDMC was positively correlated with TP content in the $0-10 \mathrm{~cm}$ soil layer. LNC was significantly negatively correlated with SOC and TN in the $0-10 \mathrm{~cm}$ soil layer, and positively correlated with AP, significantly negatively correlated with SOC, TN, and TP in 10-20 cm soil layer, and significantly negatively correlated with SOC, and TN in the $20-40 \mathrm{~cm}$ soil layer. The LPC was significantly negatively correlated with TN content in the $0-10 \mathrm{~cm}$ soil layer, with SOC and TN in the $10-20 \mathrm{~cm}$ soil layer, and with SOC, TN, AN, and AK in the $20-40 \mathrm{~cm}$ soil layer. Our results showed that N:P was significantly negatively correlated with SOC in the $0-10 \mathrm{~cm}$ soil layer, positively correlated with AP and significantly negatively correlated with SOC, TN, and TP in the 10-20 cm soil layer, and significantly negatively correlated with TN in the $20-40 \mathrm{~cm}$ soil layer. There was no significant correlation between WD and soil nutrient content.

Table 2. Correlations between leaf traits, wood density (WD), and soil nutrients in moso bamboo.

\begin{tabular}{|c|c|c|c|c|c|c|c|c|c|c|c|c|c|c|c|}
\hline & \multirow{2}{*}{$\begin{array}{c}\text { Soil } \\
\text { Layers }\end{array}$} & \multicolumn{2}{|c|}{ LA } & \multicolumn{2}{|c|}{ SLA } & \multicolumn{2}{|c|}{ LDMC } & \multicolumn{2}{|c|}{ LNC } & \multicolumn{2}{|c|}{ LPC } & \multicolumn{2}{|c|}{$\mathbf{N}: \mathbf{P}$} & \multicolumn{2}{|c|}{ WD } \\
\hline & & $\mathbf{r}$ & $p$ & $\mathbf{r}$ & $p$ & $\mathbf{r}$ & $p$ & $\mathbf{r}$ & $p$ & $\mathbf{r}$ & $p$ & $\mathbf{r}$ & $p$ & $\mathbf{r}$ & $p$ \\
\hline \multirow{3}{*}{ SOC } & $0-10$ & 0.707 & 0.160 & -0.463 & 0.356 & 0.471 & 0.346 & -0.939 & $0.005 * *$ & -0.792 & 0.060 & -0.924 & $0.009 * *$ & 0.058 & 0.914 \\
\hline & $10-20$ & 0.838 & $0.037 *$ & -0.639 & 0.171 & 0.284 & 0.585 & -0.886 & $0.019 *$ & -0.826 & $0.043 *$ & -0.825 & $0.043 *$ & 0.249 & 0.635 \\
\hline & $20-40$ & 0.906 & $0.013 *$ & -0.509 & 0.303 & 0.199 & 0.706 & -0.918 & $0.009 * *$ & -0.938 & $0.006^{* *}$ & -0.809 & 0.051 & 0.157 & 0.766 \\
\hline \multirow{3}{*}{$\mathrm{TN}$} & $0-10$ & 0.924 & $0.009 * *$ & -0.499 & 0.314 & 0.709 & 0.114 & -0.869 & 0.025 * & -0.911 & $0.012 *$ & -0.752 & 0.085 & 0.543 & 0.265 \\
\hline & $10-20$ & 0.937 & $0.006^{* *}$ & -0.694 & 0.126 & 0.506 & 0.305 & -0.962 & $0.002 * *$ & -0.899 & $0.015 *$ & -0.895 & 0.016 * & 0.414 & 0.415 \\
\hline & $20-40$ & 0.921 & $0.009^{* *}$ & -0.671 & 0.144 & 0.470 & 0.346 & -0.997 & $0.00 * * *$ & -0.899 & 0.015 * & -0.946 & $0.004^{* *}$ & 0.315 & 0.544 \\
\hline \multirow{3}{*}{$\mathrm{TP}$} & $0-10$ & 0.546 & 0.262 & -0.458 & 0.361 & 0.910 & $0.012 *$ & -0.552 & 0.256 & -0.447 & 0.374 & -0.552 & 0.256 & 0.643 & 0.168 \\
\hline & $10-20$ & 0.909 & $0.012 *$ & -0.779 & 0.068 & 0.328 & 0.526 & -0.904 & $0.013 *$ & -0.786 & 0.064 & -0.876 & $0.022 *$ & 0.381 & 0.456 \\
\hline & $20-40$ & 0.615 & 0.194 & -0.156 & 0.768 & 0.553 & 0.255 & -0.717 & 0.109 & -0.722 & 0.106 & -0.639 & 0.171 & 0.137 & 0.795 \\
\hline \multirow{3}{*}{ TK } & $0-10$ & 0.002 & 0.997 & -0.219 & 0.675 & 0.582 & 0.225 & 0.254 & 0.627 & 0.247 & 0.637 & 0.234 & 0.655 & 0.788 & 0.063 \\
\hline & $10-20$ & -0.516 & 0.294 & 0.008 & 0.988 & -0.769 & 0.074 & 0.323 & 0.532 & 0.558 & 0.249 & 0.153 & 0.772 & -0.613 & 0.196 \\
\hline & $20-40$ & 0.419 & 0.408 & -0.871 & $0.024 *$ & 0.421 & 0.405 & -0.353 & 0.493 & -0.072 & 0.892 & -0.474 & 0.343 & 0.666 & 0.149 \\
\hline \multirow{3}{*}{$\mathrm{AN}$} & $0-10$ & -0.226 & 0.667 & 0.564 & 0.244 & -0.423 & 0.403 & 0.604 & 0.204 & 0.201 & 0.703 & 0.769 & 0.074 & 0.005 & 0.993 \\
\hline & $10-20$ & 0.743 & 0.091 & -0.199 & 0.706 & 0.000 & 0.999 & -0.427 & 0.399 & -0.729 & 0.100 & -0.209 & 0.691 & 0.347 & 0.501 \\
\hline & $20-40$ & 0.918 & $0.009 * *$ & -0.475 & 0.341 & 0.177 & 0.737 & -0.747 & 0.088 & -0.893 & $0.017^{*}$ & -0.584 & 0.224 & 0.364 & 0.478 \\
\hline \multirow{3}{*}{$\mathrm{AP}$} & $0-10$ & -0.675 & 0.142 & 0.771 & 0.073 & -0.603 & 0.205 & 0.898 & 0.015 * & 0.598 & 0.210 & 0.972 & $0.001 * *$ & -0.305 & 0.556 \\
\hline & $10-20$ & -0.108 & 0.838 & 0.656 & 0.157 & -0.196 & 0.710 & 0.445 & 0.377 & -0.032 & 0.952 & 0.669 & 0.146 & 0.027 & 0.959 \\
\hline & $20-40$ & 0.458 & 0.361 & 0.292 & 0.575 & -0.070 & 0.891 & -0.157 & 0.767 & -0.603 & 0.205 & 0.114 & 0.829 & 0.109 & 0.836 \\
\hline \multirow{3}{*}{$\mathrm{AK}$} & $0-10$ & -0.245 & 0.639 & 0.529 & 0.281 & -0.206 & 0.695 & 0.643 & 0.168 & 0.253 & 0.629 & 0.797 & 0.057 & 0.185 & 0.726 \\
\hline & $10-20$ & 0.852 & $0.031 *$ & -0.482 & 0.333 & 0.058 & 0.914 & -0.621 & 0.188 & -0.777 & 0.069 & -0.466 & 0.352 & 0.386 & 0.449 \\
\hline & $20-40$ & 0.914 & $0.011 *$ & -0.554 & 0.254 & 0.148 & 0.779 & -0.751 & 0.085 & -0.853 & 0.031 * & -0.613 & 0.196 & 0.374 & 0.465 \\
\hline
\end{tabular}

SOC: soil organic carbon; TN: total nitrogen; TP: total phosphorous; TK: total potassium; AN: alkali-hydrolyzable nitrogen; AP: available phosphorous; and AK: available potassium $\left({ }^{*} p<0.05 ;{ }^{* *} p<0.01\right.$; $\left.{ }^{* *} p<0.001\right)$.

\subsection{Associations between Leaf Traits and Stand}

The first two principal components, component 1 (Dim.1) and component 2 (Dim.2), explained $66.7 \%$ and $18.7 \%$ of the variation, respectively (Figure 2). The PCA analysis showed that LPC, LNC, and N:P were negatively correlated with LA. The LDMC and WD were negatively correlated with SLA. 


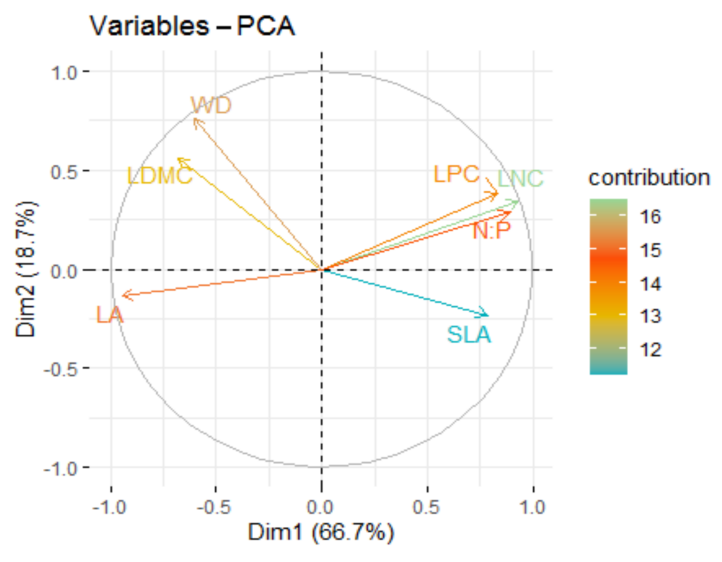

Figure 2. Principal component analysis of variables. The arrow line of the variables is plotted as the correlation coefficients between them and the first two principal components in the unit circle; colors indicate the contributions (\%) of variables to the variance in a given principal component.

\subsection{Fine Root Traits}

Fine root traits significantly decreased with increasing soil depth in both treatments (Figure 3, $p<0.05$ ). One-way analysis of variance showed that SC at the optimal width had little effect on fine root traits in different soil layers (Figure $3, p>0.05$ ).
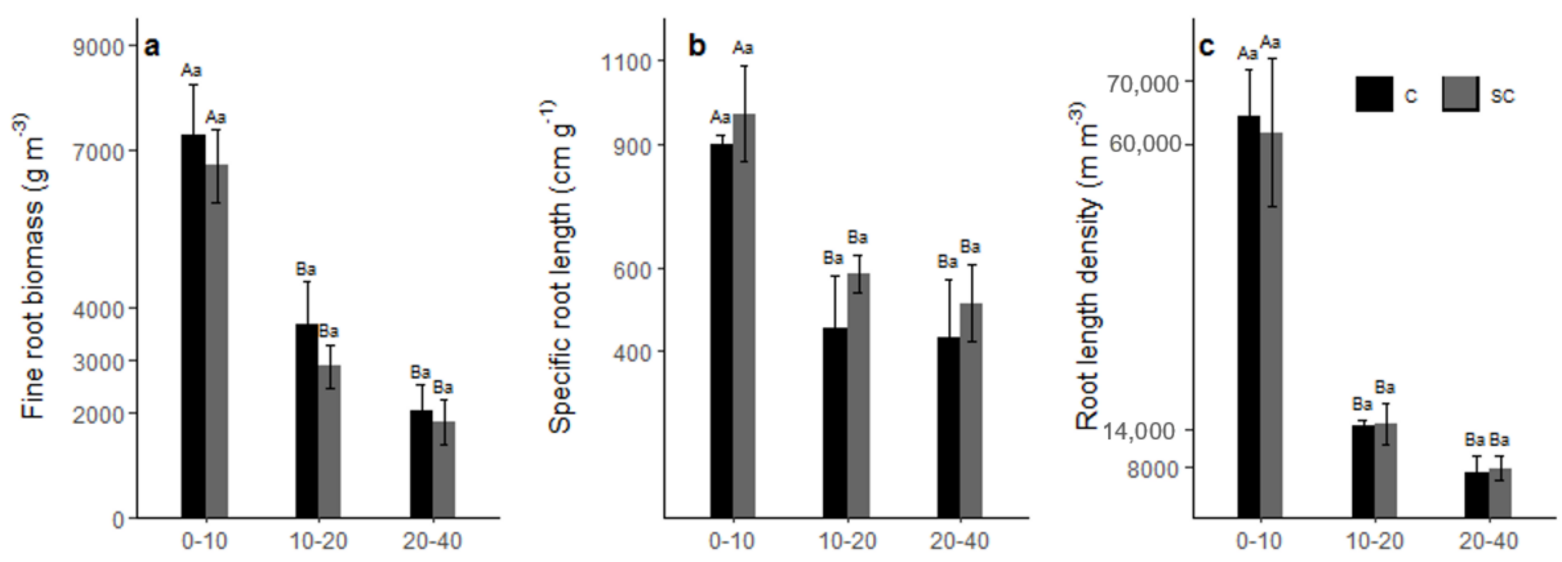

Figure 3. (a) Fine root biomass, (b) specific root length, and (c) root length density in two treatment plots (strip clearcutting (SC) and unharvested (C)). Error bars indicate the standard deviation $(n=3)$. Capital letters indicate the difference in fine root characteristics between different soil layers under the same treatment $(p<0.05)$; lowercase letters indicate differences in fine root characteristics between treatments in the same soil layer $(p<0.05)$.

\subsection{Associations between Fine Root Trait and Stand and Soil Nutrients}

The first two principal components, component 1 (Dim.1) and component 2 (Dim.2), explained $63.5 \%$ and $14.6 \%$ of the data variation, respectively (Figure 4 ). The PCA analysis showed that fine root traits (FRB, RLD, and SRL) were positively associated with SOC, TN, and TP, but negatively correlated with TK. 


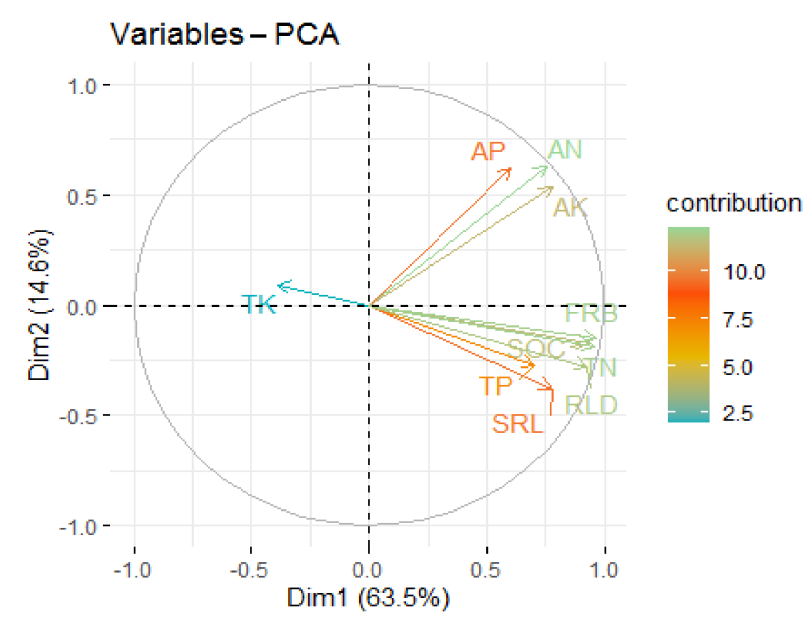

Figure 4. Principal component analysis of variables. The arrow line of the variables is plotted as the correlation coefficients between them and the first two principal components in the unit circle; colors indicate the contributions (\%) of variables to the variance in a given principal component.

\section{Discussion}

Leaves are the primary photosynthetic organs of plants and are extremely sensitive to environmental changes. Leaves are closely related to the carbon assimilation and resource utilization ability of plants, and can directly reflect the survival strategies used by plants to adapt to environmental changes [27]. Guo et al. compared leaf functional traits and environmental factors between moso bamboo and its varieties, and found that leaf functional traits were affected by soil nutrients [28]. Studies on aboveground plant parts have shown that species from environments with high nutrient availability generally display fast resource acquisition strategies, characterized by low leaf tissue density, high SLA, and high leaf nutrient concentration $[29,30]$. Thinning changed the abiotic and biotic factors in moso bamboo forests [31], which may result in different responses of functional traits. In this study, it was found that cutting significantly reduced the contents of SOC and TN in different soil layers (Table 1). Further correlation analysis showed that LA, LNC, and LPC were significantly correlated with SOC and TN (Table 2). Moreover, one-way ANOVA showed that strip cutting significantly increased LNC and LPC (Figure 1). In addition, the PCA analysis showed that LPC and LNC were negatively correlated with LA. We could conclude that the decrease in soil SOC and TN content drives the increase in LNC and LPC. We think this might be the theory of dynamic equilibrium in ecological stoichiometry. According to the theory, when the external environment fluctuates within a certain narrow range, a steady-state mechanism can be formed in the organism to keep its nutrient elements stable and achieve dynamic equilibrium [32]. The gap formed after cutting affects the light environment in the forest, and the increase in light availability usually leads to a decrease in leaf area per unit mass. The light capture area of bamboo leaves may be augmented by increasing biomass allocation in postharvest sites [33]. The allocation of plant biomass is crucial, as it determines many growth processes. It is driven by environmental conditions, and functional traits can be used as potential covariates to understand the allocation of biomass.

The N:P ratio is widely used to indicate the availability and limitations of soil nutrients. The tissue of woody plants acts as a nutrient store during active growth, allowing the newly produced, fully developed leaves to maintain the optimal N:P ratio [34]. After cutting, the nutrient concentration of new tree leaves was determined, and the N:P had increased significantly. This result demonstrates that $\mathrm{N}: \mathrm{P}$ is affected by the surrounding environment. A study evaluating the effects of plant fertilization showed that plants were restricted by $\mathrm{N}$ availability when N:P was $>14$. When the N:P value of plants was $>14$ and $<16$, they were simultaneously restricted by two elements. When the N: P was $>16$, the plant was restricted by P availability [35]. The current study found that the LNC and LPC in cut plots 
were significantly higher than those in the $C$ plots (Figure $1, p<0.05$ ). The development of new trees after cutting may be limited by $\mathrm{P}$ availability. The soil nutrient measurements showed that SOC and TN in SC were lower than in C (Table 1). The growth of aboveground vegetation requires a large quantity of nutrients, and the sample plots can only capture nutrients through absorption or remote physiological integration after harvesting, resulting in the decrease in soil SOC and TN. Long-term studies on the availability of soil nutrients after harvest have found a lag in the recovery of soil P concentration [36]. Therefore, soil $\mathrm{P}$ content may increase with plot restoration. Longer recovery time can alleviate plant $\mathrm{P}$ limitations. However, strip cutting significantly increased the soil content of AP in the 0-10 cm layer (Table 1). Correlation analysis found that AP in the $0-10 \mathrm{~cm}$ layer was significantly correlated with N:P in leaf (Table 2). Phosphorus is an essential macronutrient for higher plants, and is usually a highly mobile and frequently translocated element [37]. The increase in AP in surface layers may be due to a reduction in P utilization by surface fine roots (belonging to moso bamboo and understory vegetation) [38].

Harvesting did not affect the fine root traits $(p>0.05)$, which is consistent with our hypothesis. The powerful underground system of the moso bamboo forest plays an important role in the long-term maintenance of bamboo ecosystem function and productivity [17,39]. Fine root traits reflect plant strategies to adapt to varied environments [8] and represent fundamental trade-offs between resource acquisition and costs [40]. Fine roots can acquire nutrients and water from the soil. In this study, fine roots were mainly distributed in the 0-10 cm soil layer, as this is the most fertile layer [41]. However, SC had no effect on the fine root biomass in the moso bamboo forest (Figure 3). This finding is inconsistent with results showing that thinning increases the fine root biomass of Chinese fir plantations in southern China [42]. The difference can be explained by the unique biophysical characteristics of moso bamboo. Moso bamboo undergoes a two-year vegetative cycle called 'du', which includes both an 'on-year' and 'off-year' [43]. In the on-year, the bamboo forest produces many shoots, and stem growth requires older bamboo to transport carbon, water, and nutrients through the roots connected underground [44]. In the off-year, carbon fixed by photosynthesis is mainly used for rhizome expansions [45,46]; this is the dominant development period of the underground system [47]. The rhizome is the asexual reproductive organ of moso bamboo [46]. The functional characteristics of rhizomes of different ages increase the difficulty of studying underground ecosystems. It is well known that young rhizomes (1-2 years) have a strong expansion ability and produce additional healthy rhizomes, while older rhizomes (3-6 years) sprout shoots and turns into trees [48]. The root production has a similar growth pattern to that of the rhizomes [49], and the biomass relationship between root and rhizomes is strong [50]. However, harvesting significantly reduces the density of bamboo trees, reducing the nutrient supply to the roots. Another factor may be the decrease in carbon (C) input, which results in the senescence and death of fine roots [51]. The life span of fine roots determines their turnover rate [52]: i.e., a shorter life span increases the turnover rate of fine roots [52]. A decrease in fine root biomass is thought to relieve nutrient limitations [53]. Fan [25] used an Olson negative exponential decay model and found the annual decomposition coefficient of bamboo fine roots to be 0.6063 , and the annual turnover rate to be 0.93 . Bamboo has a higher turnover rate than other types of forest. Fine roots use a strategy of reducing biomass to increase turnover rate, and change their morphology to enhance nutrient absorption capacity. Therefore, additional soil C, through root mortality, occurs during stand development [54].

Strip clearcutting also enhanced the complementary effect of the niche, and promoted the effect of light energy on productivity in the canopy gap [55]. The gap directly increases illumination [56], and the change in thermal radiation further affects soil properties, decomposition of organic matter, and soil microbial activity [57]. In the current study, SC had a significant effect on SOC and TN (Table $1, p<0.05$ ). The principal component analysis found that the change in fine root traits was significantly related to SOC (Figure 4), which is consistent with Yang et al. [58]. The economic spectrum of plant life recognizes that higher SRL is associated with rapid resource capture [59]. According to previous studies, TN and 
TP are significantly correlated with fine root morphology and biomass $[10,39,60]$, which is consistent with the findings of this study. Phosphorus is an essential nutrient element with physiological functions in plants [37]. Umemura [45] studied the nutrient content in the organs and found that the concentrations of $\mathrm{K}$ and $\mathrm{P}$ in the younger rhizomes were higher than in the mature organs. As the amount of $\mathrm{P}$ diffused into the rhizosphere is lower than the absorption rate, the root system acquires more $\mathrm{P}$ through expansion.

\section{Conclusions}

This experiment aimed to investigate the functional response characteristics after SC in a moso bamboo forest. The results show that SC significantly decreased LA, and significantly increased LNC, LPC, and N:P. LPC, LNC, and N:P were negatively correlated with LA, while LDMC and WD were negatively correlated with SLA. The effect of cutting on fine root traits was not significant. Fine root traits (FRB, RLD, and SRL) were positively associated with SOC, TN, and TP, but negatively correlated with TK. This study highlighted that a year's recovery following cutting resulted in the root TP and TK returning to the level of uncut plots. The changes in soil nutrient content caused by the removal of biomass were normal. Improved light conditions and the rapid growth of new trees increases nutrient release; therefore, these results further confirm the effectiveness of SC.

Author Contributions: S.F. and F.G. designed this study and improved the English language and grammatical editing. Y.Z. (Yaxiong Zheng) wrote the first draft of manuscript and performed the data analysis. Y.Z. (Yaxiong Zheng) and Y.Z. (Yang Zhou) did the field works. X.J. gave guidance and methodological advice. All the coauthors contributed to the discussion, revision and improvement of the manuscript. All authors have read and agreed to the published version of the manuscript.

Funding: This research was supported by the National Key Research and Development Program of China (NO. 2018YFD0600103).

Conflicts of Interest: The authors declare no conflict of interest.

\section{References}

1. Jiang, Z.H. Bamboo and Rattan in the World; China Forest Publishing House: Beijng, China, 2007.

2. National Forestry and Grassland Administration. China Forest Resources Report; China Forest Publishing House: Beijng, China, 2019.

3. Fan, S.; Zhao, J.; Su, W.; Yu, L.; Yan, Y. Comprehensive Evaluation of Soil Quality in Phyllostachys edulis Stands of Different Stocking Stocking Densities. Sci. Silvae Sin. 2015, 51, 1-9. [CrossRef]

4. Wang, L.; Fan, C.; Liang, K.; Fan, Y.; Yang, G.; Zhang, L.; Shi, J. An Approach to a Labor-saving Cutting Model for Bamboo Forest Management-A Study Based on Clonal Integration. Acta Agric. Univ. Jiangxiensis 2016, 38, 1110-1118. [CrossRef]

5. Li, X.; Lai, J.; Yu, Z.; Li, S.; Chen, L.; He, T.; Rong, J. Effect of Different Clear Cutting Band on Physiological Indexes of Phyllostachys pubescens. Mod. Agric. Sci. Technol. 2018, 18, 122-125.

6. Zeng, X.; Su, W.; Fan, S.; Jin, Y. Qualitative Recovery Characteristics of Moso Bamboo Forests under Strip Clearcutting. Acta Bot. Boreali Occident. Sin. 2019, 39, 917-924. [CrossRef]

7. Lilli, K.; Janne, V.; Mikael, M.; Sofie, H.; Mikko, K.; Anna, S.; Marjo, P.; Helmisaari, H.-S. Stump harvesting in Picea abies stands: Soil surface disturbance and biomass distribution of the harvested stumps and roots. For. Ecol. Manag. 2018, 425, 27-34. [CrossRef]

8. Violle, C.; Enquist, B.J.; Mcgill, B.J.; Jiang, L.; Albert, C.H.; Hulshof, C.; Jung, V.; Messier, J. The return of the variance: Intraspecific variability in community ecology. Trends Ecol. Evol. 2012, 27, 244-252. [CrossRef]

9. Funk, J.L.; Larson, J.E.; Ames, G.M.; Butterfield, B.J.; Cavender-Bares, J.; Firn, J.; Laughlin, D.C.; Sutton-Grier, A.; Williams, L.; Wright, J. Revisiting the Holy Grail: Using plant functional traits to understand ecological processes. Biol. Rev. 2017, 92, 1156-1173. [CrossRef]

10. Freschet, G.T.; Bellingham, P.J.; Lyver, P.O.B.; Bonner, K.I.; Wardle, D.A. Plasticity in above-and belowground resource acquisition traits in response to single and multiple environmental factors in three tree species. Ecol. Evol. 2013, 3, 1065-1078. [CrossRef]

11. Wright, I.J.; Reich, P.B.; Westoby, M.; Ackerly, D.D.; Baruch, Z.; Bongers, F.; Cavender-Bares, J.; Chapin, T.; Cornelissen, J.H.C.; Diemer, M. The worldwide leaf economics spectrum. Nature 2004, 428, 821-827. [CrossRef]

12. Bhaskar, R.; Dawson, T.E.; Balvanera, P. Community assembly and functional diversity along succession post-management. Funct. Ecol. 2014, 28, 1256-1265. [CrossRef]

13. Ding, Y.; Zang, R. Effects of thinning on the demography and functional community structure of a secondary tropical lowland rain forest. J. Environ. Manag. 2021, 279, 111805. [CrossRef] 
14. Cheng, J.; Chu, P.; Chen, D.; Bai, Y. Functional correlations between specific leaf area and specific root length along a regional environmental gradient in Inner Mongolia grasslands. Funct. Ecol. 2016, 30, 985-997. [CrossRef]

15. Jianmin, S.; Xuehua, Y.; Fusheng, C.; Qingpei, Y.; Zuyao, L.; Kai, F. Adaptation of bamboo to heterogeneous habitat: Phenotypic plasticity. Acta Ecol. Sin. 2014, 34, 5687-5695. [CrossRef]

16. Hui, C.M.; Du, F.; Yang, Y.M. Cultivation and Utilization of Bamboo; China Forestry Press: Beijing, China, 1996.

17. Wang, Y.; Bai, S.; Binkley, D.; Zhou, G.; Fang, F. The independence of clonal shoot's growth from light availability supports moso bamboo invasion of closed-canopy forest. For. Ecol. Manag. 2016, 368, 105-110. [CrossRef]

18. Liu, X.; Feng, H.; Cai, C.; Fan, S.; Liu, G. Response of leaf functional traits of Moso bamboo during the invading process into the broad-leaved forest. J. Beijing For. Univ. 2015, 37, 8-17. [CrossRef]

19. Rui, S.; Shangbin, B.; Guomo, Z.; Yixiang, W.; Nan, W.; Guosheng, W.; Juan, C. The response of root morphological plasticity to the expansion of a population of Phyllostachys edulis into a mixed needle-and broad-leaved forest. Acta Ecol. Sin. 2016, 36, 326-334. [CrossRef]

20. Zeng, X.; Su, W.; Fan, S.; Jing, X.; Chu, H. Soil quality assessment in Moso bamboo forests under different strip clearcutting. Chin. J. Ecol. 2019, 38, 3015-3023. [CrossRef]

21. Zhan, M.; Guan, F.; Yan, Y.; Zhang, M.; Zheng, Y. Effects of strip harvesting on species diversity of undergrowth in bamboo (Phyllostachys Edulis) forest. Acta Ecol. Sin. 2020, 40, 4169-4179. [CrossRef]

22. Li, L.; Li, N.; Lu, D.; Chen, Y. Mapping Moso bamboo forest and its on-year and off-year distribution in a subtropical region using time-series Sentinel-2 and Landsat 8 data. Remote Sens. Environ. 2019, 231, 111265. [CrossRef]

23. JT, T.; DJ, R. Use of nitrogen to phosphorus ratios in plant tissue as an indicator of nutrient limitation and nitrogen saturation. J. Appl. Ecol. 2003, 40, 523-534. [CrossRef]

24. State Bureau of Technical Supervision. Testing Methods for Physical and Mechanical Properties of Bamboo; Standard Press of China Beijing: Beijing, China, 1995.

25. Shaohui, F.; Fuming, X.; Silong, W.; Wenhui, S.; Xiaojun, Y.; Zhengqi, S. Fine Root Biomass and Turnover in Moso Bamboo Plantation in Huitong Forest Station, Hunan Province. Sci. Silvae Sin. 2009, 45, 1-6. [CrossRef]

26. Liu, G.; Fan, S.; Cai, C.; Liu, X.; Li, Y.; Luo, T. Fine Root Biomass Distribution of Moso Bamboo at Different Ages. J. Trop. Subtrop. Bot. 2017, 25, 472-479.

27. Lawren, S.; Christine, S.; John, G.P.; Hendrik, P.; Mason, C.M.; Rodrigo, M.A.; Donovan, L.A. How do leaf veins influence the worldwide leaf economic spectrum? Review and synthesis. J. Exp. Bot. 2013, 64, 4053-4080. [CrossRef]

28. Wen, G.; Jian, Z.; Lianghua, Q.; Ze'an, S.; Rui, W.; Chang, Y. Leaf functional traits and influencing factors of Phyllostachys edulis and its varieties. J. For. Environ. 2020, 40, 260-268. [CrossRef]

29. Jager, M.M.; Richardson, S.J.; Bellingham, P.J.; Clearwater, M.J.; Laughlin, D.C. Soil fertility induces coordinated responses of multiple independent functional traits. J. Ecol. 2015, 103, 374-385. [CrossRef]

30. Ordoñez, J.C.; Bodegom, P.M.V.; Witte, J.P.M.; Wright, I.J.; Reich, P.B.; Aerts, R. A global study of relationships between leaf traits, climate and soil measures of nutrient fertility. Glob. Ecol. Biogeogr. 2010, 18, 137-149. [CrossRef]

31. Inoue; Tateishi; Sakuta; Yamamoto; Mizoue; Kitahara. Relationships of light environment to stand attributes in a stand of bamboo, Phyllostachys pubescens. Ecol. Eng. 2012, 38, 135-139. [CrossRef]

32. Zhang, L.-X.; Bai, Y.-F.; Han, X.-G. Application of N:P Stoichiometry to Ecology Studies. Acta Bot. Sin. 2003, 45, 1009-1018.

33. Yin, Q.; Tian, T.; Han, X.; Xu, J.; Chai, Y.; Mo, J.; Lei, M.; Wang, L.; Yue, M. The relationships between biomass allocation and plant functional trait. Ecol. Indic. 2019, 102, 302-308. [CrossRef]

34. Schreeg, L.A.; Santiago, L.S.; Wright, S.J.; Turner, B.L. Stem, root, and older leaf N:P ratios are more responsive indicators of soil nutrient availability than new foliage. Ecology 2014, 95, 2062-2068. [CrossRef] [PubMed]

35. Koerselman, W.; Meuleman, A. The Vegetation N:P Ratio: A New Tool to Detect the Nature of Nutrient Limitation. J. Appl. Ecol. 1996, 33, 1441-1450. [CrossRef]

36. Hume, A.M.; Chen, H.Y.H.; Taylor, A.R. Intensive forest harvesting increases susceptibility of northern forest soils to carbon, nitrogen and phosphorus loss. J. Appl. Ecol. 2018, 55, 246-255. [CrossRef]

37. White, P. Long-distance Transport in the Xylem and Phloem. In Marschner's Mineral Nutrition of Higher Plants, 3rd ed.; Elsevier: Adelaide, Australia, 2012; pp. 49-70.

38. Liu, G. Study on the Mechanism of Maintaining Long-term Productivity of Bamboo Forest; Chinese Academy of Forestry: Beijing, China, 2019.

39. Freschet, G.T.; Valverde-Barrantes, O.J.; Tucker, C.M.; Craine, J.M.; Mccormack, M.L.; Violle, C.; Fort, F.; Blackwood, C.B.; Urban-Mead, K.R.; Iversen, C.M. Climate, soil and plant functional types as drivers of global fine-root trait variation. J. Ecol. 2017, 105, 1182-1196. [CrossRef]

40. Wurzburger, N.; Wright, S.J. Fine-root responses to fertilization reveal multiple nutrient limitation in a lowland tropical forest. Ecol. A Publ. Ecol. Soc. Am. 2015, 96, 2137-2146. [CrossRef]

41. Weng, F.; Wang, K.; He, Q.; Wu, R. Absorbing ability of root and rhizome system of Phyllostachys pubescens shoot forest at different ages. J. Zhejiang A F Univ. 2001, 18, 28-30. [CrossRef]

42. Wang, D.; Olatunji, O.A.; Xiao, J. Thinning increased fine root production, biomass, turnover rate and understory vegetation yield in a Chinese fir plantation. For. Ecol. Manag. 2019, 440, 92-100. [CrossRef] 
43. Tang, X.; Qi, L.; Fan, S.; Guan, F.; Zhang, H. Soil respiration and net ecosystem production in relation to intensive management in Moso bamboo forests. Catena 2016, 137, 219-228. [CrossRef]

44. Zhang, L.; Wen, G.; Zhang, R.; Wang, D.; Zhang, J. Climate change response using a simulation study of photosynthetic physiology on Phyllostachys pubescens. J. Zhejiang A F Univ. 2011, 28, 555-561. [CrossRef]

45. Umemura, M.; Takenaka, C. Retranslocation and localization of nutrient elements in various organs of moso bamboo (Phyllostachys pubescens). Sci. Total Environ. 2014, 493, 845-853. [CrossRef]

46. Tong, L.; Li, P.; Zhou, G.; Zhou, Y.; Li, C. A review of research about rhizome-root system in bamboo forest. J. Zhejiang A F Univ. 2019, 36, 183-192. [CrossRef]

47. Chapin, F.S.; Matson, P.A.; Mooney, H.A. Principles of Terrestrial Ecosystem Ecology; Springer: Berlin/Heidelberg, Germany, 2011.

48. Zhong, Y.; Jiang, X.; Lou, C. Research progress in growth rhythm of bamboos. World Bamboo Ratt. 2014, 12, 35-44. [CrossRef]

49. Wu, M.; Han, D.; Wand, J. Studies on the roots of young artificial seedling stands of Phyllostachys pubescens. Sci. Silv. Sin. 1984, 20, 201-204.

50. Jiang, G.; Yu, L.; Li, Z.; Niu, H.; Shi, L. Hierarchical system and its quantitative attribute of moso bamboo rhizome. Chin. J. Ecol. 2017, 36, 3479-3484. [CrossRef]

51. Eissenstat, D.; Yanai, R. The ecology of root lifespan. In Advances in Ecological Research; Elsevier: Amsterdam, The Netherlands, 1997; Volume 27, pp. 1-60.

52. Schoettle, A.W.; Fahey, T.J.; Shoettle, A.W. Foliage and fine root longevity of pines. Ecol. Bull. 1994, 43, $136-153$.

53. Ostertag; Rebecca. Effects of Nitrogen and Phosphorus Availability on Fine-Root Dynamics in Hawaiian Montane Forests. Ecology 2001, 82, 485-499. [CrossRef]

54. Zhu, K.; Song, Y.; Qin, C. Forest age improves understanding of the global carbon sink. Proc. Natl. Acad. Sci. USA 2019, 116, 3962-3964. [CrossRef]

55. Yachi, S.; Loreau, M. Does complementary resource use enhance ecosystem functioning? A model of light competition in plant communities. Ecol. Lett. 2010, 10, 54-62. [CrossRef]

56. Yirdaw, E.; Luukkanen, O. Photosynthetically active radiation transmittance of forest plantation canopies in the Ethiopian highlands. For. Ecol. Manag. 2004, 188, 17-24. [CrossRef]

57. Wang, J.; Zhang, Y. A Review on Within-gap Micro-environmental Heterogeneity and Species' Response. J. Nanjing For. Univ. 2002, 26, 69-74. [CrossRef]

58. Chuanbao, Y.; Xiaoping, Z.; Huijing, N.; Xu, G.; Zheke, Z. Soil carbon and associated bacterial community shifts driven by fine root traits along a chronosequence of Moso bamboo (Phyllostachys edulis) plantations in subtropical China. Sci. Total Environ. 2021, 752, 142333. [CrossRef]

59. Westoby, M.; Wright, I. Land-plant ecology on the basis of functional traits. Trends Ecol. Evol. 2006, 21, 261-268. [CrossRef] [PubMed]

60. Wang, D. The Effect of Thinning on Fine Root Morphology, Nutrients and Turnover of Chinese Fir Plantations; Nanjing Forestry University: Nanjing, China, 2013. 